\section{EDUCAÇ̃̃̃O}

V.9 • N.2 • 2020 - Número Temático

ISSN Digital: 2316-3828

ISSN Impresso: 2316-333X

DOI: 10.17564/2316-3828.2020v9n2p66-80
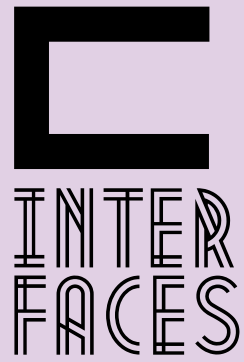

CIENTIFICAS

\title{
O COMPUTADOR INTERATIVO NO ENSINO DE MATEMÁTICA: CARTOGRAFANDO AS VOZES DOS PROFESSORES
}

THE INTERACTIVE COMPUTER IN MATHEMATICS TEACHING: CARTOGRAPHING THE TEACHERS 'VOICES

\section{EL COMPUTADOR INTERACTIVO EN LA ENSEÑANZA DE MATEMÁTICA: CARTOGRAFIANDO LAS VOCES DE LOS PROFESORES}

José Elyton Batista dos Santos ${ }^{1}$ Carlos Alberto Vasconcelos ${ }^{2}$

\section{RESUMO}

0 presente artigo tem como objetivo investigar os processos de inserção do computador interativo com lousa digital no ensino de Matemática na rede municipal de Coruripe (Alagoas). Trata-se de um estudo de natureza qualitativa delimitada sob o método cartográfico, pelo fato de estudar os fenômenos processuais e subjetivos que emergem nos diversos espaços sociais. Optou-se pelas técnicas da entrevista semiestruturada e diário de campo. Os caminhos foram flexivelmente traçados e se direcionaram aos protagonistas/sujeitos, ou seja, três professores de Matemática. Os resultados revelam que o computador interativo está sendo inserido na sala de aula de forma limitada, não fazendo uso de todas as suas funcionalidades: computador, projetor e lousa digital interativa. Os professores expressam que sua prática pedagógica está inserida em um mundo bidimensional, contudo a falta de formação continuada e direcionada especificamente para esse fim tem ocasionado empecilhos em sua utilização.

\section{PALAVRAS-CHAVE}

Professores de Matemática. Computador interativo. Prática Pedagógica. Mundo Bidimensional. 


\section{ABSTRACT}

This article aims to investigate the processes of insertion of the interactive computer with a digital blackboard in the teaching of Mathematics in the municipal network of Coruripe (Alagoas). It is a qualitative study delimited under the cartographic method, due to the fact that it studies the procedural and subjective phenomena that emerge in the various social spaces. We opted for the techniques of semi-structured interview and field diary. The paths were flexibly traced and addressed to the protagonists / subjects, that is, three mathematics teachers. The results reveal that the interactive computer is being inserted into the classroom in a limited way, not making use of all its functionalities: computer, projector and interactive digital whiteboard. Teachers express that their pedagogical practice is inserted in a two-dimensional world, however the lack of continued training and specifically directed to this end has caused obstacles in its use.

\section{KEYWORDS}

Mathematics Teachers. Interactive Computer. Pedagogical Practice. Two-Dimensional World.

\section{RESUMEN}

Este artículo tiene como objetivo investigar los procesos de inserción de la computadora interactiva con una pizarra digital en la enseñanza de las Matemáticas en la red municipal de Coruripe (Alagoas). Es un estudio cualitativo delimitado bajo el método cartográfico, debido al hecho de que estudia los fenómenos procesales y subjetivos que emergen en los diversos espacios sociales. Optamos por las técnicas de entrevista semiestructurada y diario de campo. Los caminos fueron trazados de manera flexible y dirigidos a los protagonistas/personas, es decir, tres profesores de matemáticas. Los resultados revelan que la computadora interactiva se está insertando en el aula de manera limitada, sin hacer uso de todas sus funcionalidades: computadora, proyector y pizarra digital interactiva. Los maestros expresan que su práctica pedagógica se inserta en un mundo bidimensional, sin embargo, la falta de capacitación continua y dirigida a este fin ha causado obstáculos en su uso.

\section{PALABRAS CLAVE}

Profesores de matemática. Computadora interactiva. Práctica pedagógica. Mundo bidimensional. 


\section{INTRODUÇ̄̃̃O}

As relações subjetivas da sociedade contemporânea estão presentes nos diferentes tipos de culturas e espaços, sendo representadas nesse âmbito formas de expressões e linguagens de acordo com os costumes locais, regionais, nacionais ou até internacionais. Esse sistema integrador cultural de produção da subjetividade é denominado por Castells (1999) como uma língua universal digital e dá-se pela estruturação de um novo modo de relacionar-se, oriundo do desenvolvimento do informacionalismo (uso de tecnologias para o processamento de informações e comunicação).

Guattari (1992, p. 14) ressalta que “[...] as máquinas tecnológicas de informação e comunicação operam no núcleo da subjetividade humana, não apenas no seio das suas memórias, da sua inteligência, mas também da sua sensibilidade, dos seus afetos, dos seus fantasmas inconscientes". Assim, essas dimensões tecnológicas provocam nos indivíduos a heterogeneidade, manifestada no meio ambiente (ou em outros recintos), no contexto familiar e na educação.

No ambiente educacional, o ensino das diferentes áreas do conhecimento tem como recursos adjacentes diferentes tecnologias que dão suporte, colaboram, facilitam, agilizam e acrescentam informações para a formação de indivíduos. Todavia, os olhares e pensamentos dos alunos estão fixados principalmente em um novo mundo da sociedade contemporânea, o digital, sendo denominado, a partir desse contexto, como Sociedade Informacional - "rede digital, acesso fácil e rápido à informação" (OLIVEIRA, E. V., 2017, p. 27).

Castells (1999, p. 39) chama esse momento de uma "nova estrutura social" caracterizada pelo surgimento e desenvolvimento de uma nova fonte de produtividade, as tecnologias digitais, que são responsáveis pela nova forma de informação e comunicação, ou melhor, pelas relações subjetivas estabelecidas entre sujeitos por meio de instrumentos tecnológicos.

Por sua vez, essa sociedade traz um desafio enorme para a escola, qual seja, inserir, integrar e formar continuamente seus agentes (professores e demais profissionais da educação), para assim poder acompanhar essas mudanças de paradigma. Logo, "uma característica marcante do século XXI é a mudança na maneira das [sic] pessoas se comunicarem. A velocidade que [sic] a informação movimenta-se de um local para outro do globo é surpreendente" (OLIVEIRA, E. V., 2017, p. 27).

Essa disseminação de informação é gerenciada pela conjunção de minúsculos elementos, os bits. No momento de comunicação ou informação via meios digitais, não é a matéria que está sendo transportada, mas os bits em formas de representações. Contudo, há uma interligação entre a matéria e os bits, pois, mesmo em uma sociedade digital, os átomos continuam a existir.

Todavia, encontram-se cada vez mais em minoria, em perda de olhares, espaços e novas formas de relações sociais, sendo dominados pelo mundo digital. Quanto ao âmbito escolar, o Ministério da Educação (MEC), por meio do Programa Nacional de Tecnologia Educacional (PROINFO), busca permear nas escolas o mundo bidimensional inerente à comunidade externa a elas.

Nesse sentido, mais precisamente tratando-se da educação brasileira em termos tecnológicos ou das tecnologias da informação e comunicação (TIC) e de políticas públicas para a inserção das TIC nas escolas 
brasileiras, o presente trabalho tem como objetivo investigar os processos de inserção do computador interativo com lousa digital no ensino de Matemática da rede municipal de Coruripe em Alagoas.

Desse modo, de forma a atender o referido objetivo, procurou-se discorrer sobre o Prolnfo, por se tratar do programa responsável pela inserção de diversas tecnologias e cursos de formação continuada para o uso pedagógico de dispositivos tecnológicos nas escolas públicas brasileiras, em especial no estado de Alagoas, mais precisamente no município de Coruripe, assim como, a respeito de trechos cartográficos das experiências e vivências dos professores de Matemática com o uso do computador interativo com lousa digital em suas aulas.

Vale destacar que o presente artigo é um recorte da pesquisa intitulada Do pó de giz aos bits: cartografando os processos de adesão e inserção do computador interativo no ensino de Matemática, desenvolvida no Mestrado em Ensino de Ciências e Matemática, no Programa de Pós-Graduação em Ensino de Ciências e Matemática (NPGECIMA), pela Universidade Federal de Sergipe, em 2018.

\section{POLÍTICAS PARA O USO PEDAGÓGICO DAS TIC E A FORMAÇ̃̃̃O: PROINFO}

Perante o cenário evolutivo e histórico das tecnologias na sociedade, o MEC, com suas atribuições, fomenta, por meio do Prolnfo, o uso das TIC pelas instituições públicas de ensino, mais precisamente as da educação básica. Incentivam-se, assim, a inserção e o uso das tecnologias como instrumento pedagógico nas salas de aula. Perante esse contexto, buscou-se discorrer a princípio sobre as ações do Prolnfo no estado de Alagoas e principalmente no município de Coruripe.

\subsection{PROINFO NO ESTADO DE ALAGOAS E NO MUNICÍPIO DE CORURIPE-AL}

No estado de Alagoas, o Prolnfo deu-se a partir de convênio entre o MEC e a Secretaria de Estado da Educação de Alagoas, em 30 de junho de 1998, com o objetivo de integrar as escolas ao mundo tecnológico e formar os professores para atuarem em laboratórios de informática.

Sua implementação deu-se a partir de três iniciativas: adesão ao Prolnfo; implantação de dois Núcleos de Tecnologia Educacional (NTE), sendo um na capital do estado, Maceió, outro no interior, no município de Arapiraca; e oferta de um curso de especialização realizado na UFAL destinado à preparação de professores, de maneira a atuarem como multiplicadores dos conhecimentos tecnológicos para as escolas estaduais e municipais (AZEVEDO, 2009).

O curso de especialização Formação de Formadores em Informática, organizado pela Universidade Federal de Alagoas (UFAL), focalizou a linguagem de programação Logo, recebendo uma grande resistência por parte dos futuros formadores (AZEVEDO, 2009). Após certa rejeição, os professores encaminharam uma solicitação à Coordenação Estadual de Tecnologia Educacional (CETE) para que fosse modificado o supracitado curso, pelo fato de não propor uma formação com objetivo pedagógico. Assim, a Cete procurou ofertar outros cursos de formação continuada de acordo com o que os professores almejavam. Dessa forma, foram oferecidos os seguintes cursos: 
Curso de informática instrumental (1999), curso de concepções teóricas da informática educativa (1999), pedagogia de projetos (1999), internet aplicada à educação (2000), Curso Básico de 4 (2000/2001), uso pedagógico dos recursos do Office (2001) e integração TV Escola/PROINFO (2000/2001). (AZEVEDO, 2009, p. 3-4).

Entretanto, ao longo do período, poucas escolas estaduais e municipais foram beneficiadas com os referidos cursos. Somente a retomada do Prolnfo em 2007 possibilitou a adesão de outros municípios alagoanos e a criação da Coordenação Estadual no âmbito da União Nacional dos Dirigentes Municipais de Educação (UNDIME) para atendimento aos municípios.

Essa nova fase do Prolnfo possibilitou para as escolas públicas da educação básica do estado de Alagoas a distribuição de novos laboratórios, a criação do Programa Banda Larga nas Escolas (ampliação de internet nas escolas) e a elaboração conjunta do Prolnfo Integrado, que compreende três cursos: Introdução à Educação Digital (40h); Ensinando e Aprendendo com as TIC (100h) e Elaboração de Projetos (40h) (AZEVEDO, 2009).

Nesse contexto, insere-se o Município de Coruripe. Sua integração ao Prolnfo deu-se somente no ano de 2009, com a implantação dos laboratórios de informática e as formações aos professores.

A Informática na Educação que o MEC-PROINFO tem adotado enfatiza o fato de o professor da disciplina curricular ter conhecimento sobre os potenciais educacionais do computador e ser capaz de alterar adequadamente atividades tradicionais de ensino-aprendizagem e atividades que usam a referida máquina. (ARAÚJO, 2009, p. 1).

No ano de 2010, a rede municipal de Coruripe é surpreendida com outras políticas públicas do Prolnfo, a exemplo do Projeto Um Computador Por Aluno - UCA (entrega de um laptop educacional para cada aluno da instituição escolar (São Rafael, localizada no povoado Bonsucesso) e a formação continuada em informática para todos os professores e funcionários da rede municipal de ensino com o objetivo de conhecerem o computador e o seu sistema operacional (Linux).

As ações de formação continuada continuaram até o final de 2011. O retorno do município ao Prolnfo deu-se em 2016, com a adesão ao computador interativo com lousa digital, sendo também conhecido pelos professores da rede municipal de Coruripe como projetor laranjão/amarelão ou datashow.

\subsection{COMPUTADOR INTERATIVO COM LOUSA DIGITAL}

A mutação do quadro-negro aos bits já estava sendo prevista pelos processos transformativos nos quais essa tecnologia vinha transitando nas últimas décadas, por exemplo, do quadro verde, branco ou de vidro para as Lousas Digitais Interativas (LDI). Contudo, as LDI somente inseriram-se nos sistemas educacionais do ensino brasileiro no início do século XXI.

Segundo Bastos (2005, p. 3), a edição da Revista Época do dia 8 de julho de 2002 anunciava a lousa digital. A reportagem trazia: "O sucessor do quadro-negro, em que mostra sua substituição por uma plataforma sensível ao toque, denominada lousa digital interativa [...]”. Seria esse o sinal de uma 
transformação da sala de aula do século XXI, mas com permanência organizacional do século XX?

Após dezesseis anos de sua incorporação nos espaços escolares brasileiros, ainda não é possível concordar com a citada reportagem. Entretanto, as tecnologias têm evoluído vertiginosamente nas últimas décadas, podendo originar outros formatos sinônimos ao quadro-negro, ou, no mais tardar, uma transformação por completo da sala de aula, do mundo dos átomos aos bits. Essa afirmação deve-se à gradativa mudança ou à diversidade de recursos tecnológicos na escola contemporânea.

Mas o que vem a ser a LDI? De acordo com Silva (2016, p. 38), trata-se de “um recurso tecnológico contemporâneo que nos permite inovar durante as aulas, através de suas variadas ferramentas e com o acesso à internet em sua própria tela. Para funcionar, deve ser integrada a um computador, bem como a um projetor de imagem”. Corroborando isso, Esteves, Fiscarelli e Souza (2013, p. 188) expõem o seguinte:

A lousa digital interativa compreende um conjunto de equipamentos tecnológicos organizados de forma a cumprir uma tarefa específica. Esses equipamentos são: um sistema de interação motora com os usuários; um projetor, para projetar as informações do computador; o computador, que comanda todas as interações, e o software da lousa digital, que oferece diversas ferramentas possibilitando que seus usuários prepararem atividades, apresentações e ações, conjuntamente aos demais aplicativos do computador.

A LDI, ou seja, o Computador Interativo com Lousa Digital, surgiu de uma parceria entre o MEC e duas universidades públicas brasileiras - Universidade Federal de Santa Catarina e Universidade Federal de Pernambuco -, com o intuito de desenvolver um só equipamento com projetor, computador, televisão, aparelho de som, microfone, wi-fie DVD. Os municípios, estados e o Distrito Federal realizaram a adesão ao programa Prolnfo para a compra dos computadores interativos com lousa digital de forma on-line, sendo atualmente feita a partir do Sistema de Gerenciamento de Atas e Registros de Preço (SIGARP) (BRASIL, 2017).

Compreende, por meio das atas, um quantitativo de 450 mil unidades ofertadas pelo Fundo Nacional de Desenvolvimento da Educação (FNDE)/MEC às escolas públicas brasileiras. Nessa perspectiva, as tecnologias desse tipo tendem a se expandir "exponencialmente em razão de sua capacidade de criar uma interface entre campos tecnológicos mediante uma linguagem digital comum na qual a informação é gerada, armazenada, recuperada, processada e transmitida" (CASTELLS, 1999, p. 68).

O computador interativo de modelo PC - 3500I, fabricado pela empresa Urmet Daruma Telecomunicação e Informática S.A, é uma tecnologia fácil de instalar e manusear. Apresenta características de: microcomputador, amplificador de áudio, projetor e lousa digital interativa, com unidade de desempenho suficiente para reproduzir vídeos e áudios em tela cheia, sem que haja distorções, travamentos ou retardos nas reproduções dos vídeos ou áudios.

A conjunção de todos esses elementos em um único equipamento colabora para o professor desenvolver a aula planejada sem um considerável quantitativo de instrumentos tecnológicos que, em algumas situações, precisariam de ajustes, como conectar caixinhas de som, extensões para centralizar o instrumento na sala ou em uma distância que ampliasse a projeção, entre outros fatores, tomando um bom tempo da aula. Assim, 
[...] estas tecnologias podem otimizar o trabalho de sala de aula e mobilizar a socialização de saberes e a construção de sentidos no processo de ensino e de aprendizagem, reforçando a rápida e eficiente transmissão de informações, criando condições para uma maior interação entre os sujeitos envolvidos num espaço fluido e dinâmico que permite a ação, a participação, a livre problematização, bem como a liberdade de expressão. (OLIVEIRA, C. A., 2017a, p. 7).

Outro diferencial do computador interativo é propor aos professores a lousa digital, permitindo a interatividade entre aluno e máquina. Nesse contexto, “a interatividade pressupõe a troca, o diálogo, o fazer junto. Enquanto isso, ainda estamos acostumados com uma educação centrada na transmissão de informações e conhecimento pelo professor" (VASCONCELOS, 2017, p. 79). 0 autor ainda acrescenta que a interatividade não se limita apenas à interação digital, visto que as tecnologias e as telemáticas ampliam as possibilidades de troca, intercâmbio e intervenções nos diferentes recursos, ou a interação com algum indivíduo a qualquer distância.

Segundo Vicentin (2017, p. 26), a LDI também oferece ações desse tipo, sendo esse seu grande diferencial, uma vez que a sua

[...] utilização como instrumento de interação, através do toque com a caneta digital diretamente no quadro, possibilita interatividade entre pessoas e máquina. Portanto, esse recurso tecnológico possibilita a inserção da interatividade e interação no espaço escolar.

Com a utilização de softwares pedagógicos ou recursos didáticos on-line, consequentemente sendo um aliado no processo de ensino e aprendizagem, em especial para a Matemática.

Todavia, cada TIC tem sua peculiaridade, sendo necessário oferecer continuamente formações ao professor para inserir em sala de aula por completo os recursos disponíveis em determinadas tecnologias digitais e, assim, integrá-las de modo a realizar uma quebra de paradigmas no ensinar e na construção dos conhecimentos, contribuindo, desse modo, para a aprendizagem dos alunos.

\section{METODOLOGIA}

A partir da dinâmica e complexidade em que se dão o contexto educacional e precisamente o ensino, há uma necessidade de limitar o objeto de estudo para uma melhor compressão dos fenômenos no âmbito escolar e na prática pedagógica do professor, em especial o de Matemática. Nesse sentido, optou-se por uma abordagem de natureza qualitativa, delimitando-se no Método Cartográfico. 


\section{Figura 1 - Configuração do Método cartográfico}

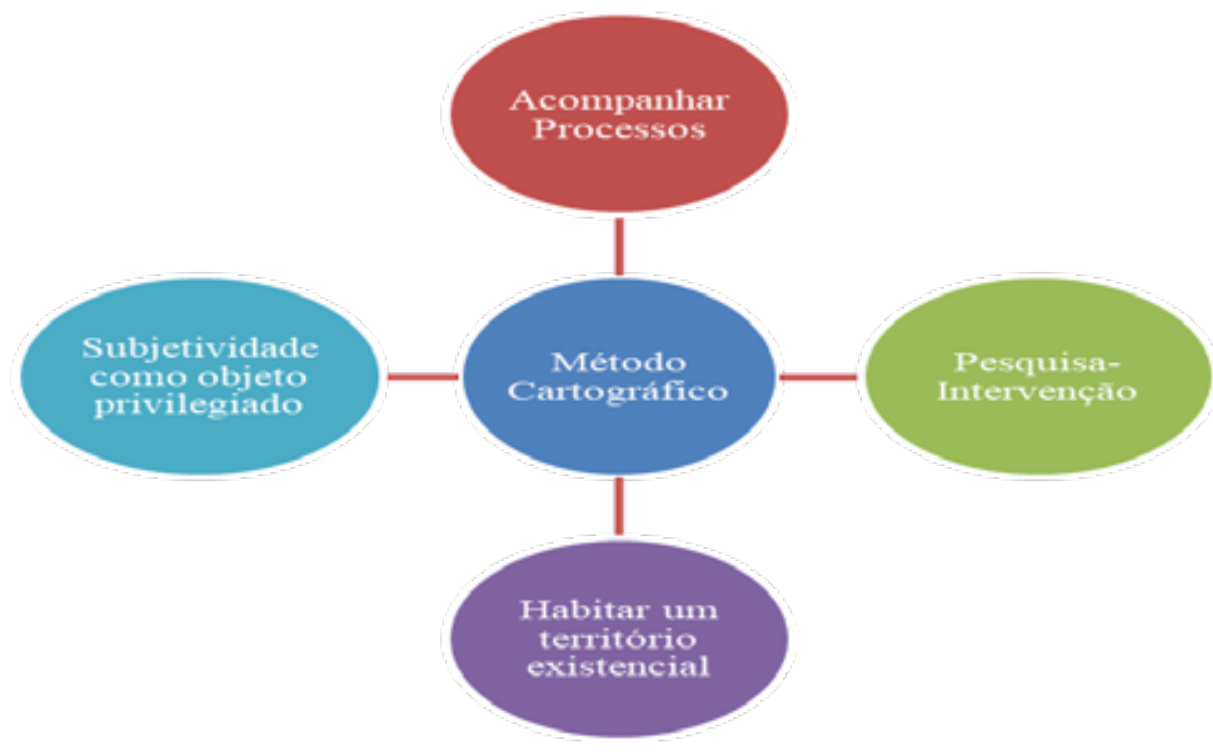

Fonte: Os autores (2018).

Segundo Passos e Barros (2015, p. 17), “toda pesquisa é intervenção”. Essa parte dimensional do método cartográfico relaciona-se ou emerge do caminhar em busca de conhecer os processos resultantes das políticas sociais presentes em um grupo ou diferentes grupos.

Conhecer é acompanhar seu processo de constituição, o que não pode realizar sem uma imersão no plano de experiência. Conhecer o caminho de constituição de dado objeto equivale a caminhar com esse objeto, constituir esse próprio caminho, constituir-se no caminho. Esse é o caminho da pesquisa-intervenção. (PASSOS; BARROS, 2015, p. 31).

Nessa perspectiva, fazer uma pesquisa de campo é intervir sobre os processos nos quais se deu ou se dá o objeto. Em síntese, é buscar a investigação da dimensão processual da realidade de um determinado contexto ou espaço a partir da participação de um grupo heterogêneo. De modo geral, o método cartográfico caracteriza-se como um instrumento de pesquisa de campo no estudo da subjetividade.

Nesse sentido, este trabalho buscou compreender, a partir das vozes dos professores de Matemática da rede municipal de Coruripe, os processos de inserção do computador interativo com lousa digital no processo de ensino-aprendizagem. Assim, os sujeitos/protagonistas foram três professores de Matemática (P1, P2, P3) que lecionam na referida rede de ensino e fazem uso do computador interativo.

A entrevista e o diário de campo foram os instrumentos utilizados para a coleta dos dados, a produção e o compartilhamento dos processos desenvolvidos ou que estão acontecendo na rede municipal de ensino. 
A escolha desses instrumentos deu-se pelo fato de serem fontes de informações da pesquisa qualitativa e como técnica para a produção da subjetividade, exercendo, desse modo, uma função cartográfica.

Vale destacar que o método cartográfico não exige nenhum manejo de análise, pois visa a explicar uma realidade por meio das partes de um todo em elementos que a compõem, ou melhor, exerce um papel reflexivo e dialógico ao longo dos fatos narrados. Assim, "a análise está presente em todo o processo de pesquisa, e não apenas em sua conclusão” (BARROS; BARROS, 2016, p. 192).

\section{RESULTADOS}

Os resultados apresentam a produção do que foi coletado perante os caminhos percorridos pelo cartógrafo e as entrevistas realizadas, levando em consideração o diário de campo e os manuscritos resultantes das vozes dos protagonistas, a fim de desenvolver narrativas cartográficas sobre os processos de inserção do computador interativo com lousa digital no ensino de Matemática da rede municipal de Coruripe.

\section{1 AS VOZES DOS PROFESSORES DE MATEMÁTICA E O COMPUTADOR INTERATIVO}

As relações existentes nos diferentes contextos tendem a ter uma maior dimensão ao longo do aumento de afazeres dos seres humanos para sobreviverem e agilizarem alguns processos que se inserem no cotidiano. Nessa perspectiva, os professores deparam-se continuamente com propostas ou orientações metodológicas que ressingularizam o seu ensinar e modificam a processualidade repetitiva, salvo raras exceções.

Ao longo da caminhada, buscou-se compreender a concepção pedagógica do professor de Matemática centrada na dimensão tecnológica, em especial, com o uso do computador interativo com lousa digital. A palavra concepção é um termo difícil de conceituar, mas, neste estudo, refere-se ao “[...] que a pessoa pensa sobre determinada coisa, que entendimento tem dessa coisa, qual é a forma como ela a vê ou encara" (GUIMARÃES, 2010, p. 83). Assim, as tecnologias são compreendidas como "dispositivos/aparelhos que são capazes de transmitir informações de maneira rápida e detalhada, de modo a atingir um número maior de pessoas em menos tempo" ( $\mathrm{P} 1)$.

Pode ser dito, a partir dessa perspectiva, que as tecnologias digitais estão difundidas no meio social, sendo compreendidas como mais um artifício utilizado para obter informações, conhecimentos e também comunicação. Diante dessa vertente, o professor P2 destaca que a tecnologia veio para um melhor desenvolvimento do sistema educacional como um todo:

$\mathrm{Na}$ escola, facilita o professor e ajuda no desempenho do aluno. Ao longo dos meus 17 anos de profissão, acompanhei um processo de evolução das tecnologias em sala de aula. A tecnologia no início da minha prática docente era o quadro, giz e o livro didático. Logo após surgiu o datashow e o computador, onde o quadro e giz continuaram fazendo parte dos meus recursos, mas ao mesmo tempo os considero ultrapassados, comparando com as tecnologias atuais. Agora surge o amarelão, ele também vem deixando o datashow sem utilização, já que no próprio amarelão tem projeção, além de outras funções. 
Desse modo, o protagonista P2 expressa situações de transições históricas presenciadas ao longo da sua trajetória profissional. Outro fato interessante são suas considerações em relação à visão tecnológica (quadro, giz, livro didático - mundo dos átomos) e ao surgimento de meios digitais (datashow e amarelão) em seu contexto. A designação dada a essa última TIC é um apelido dado ao computador interativo com lousa digital. Perante as vozes dos protagonistas, foi possível identificar reflexões acerca das tecnologias convencionais para a escola, na sala de aula (quadro-negro, giz e livro didático), assim como das tecnologias onipresentes na sociedade contemporânea.

Para Oliveira (2018), em uma sociedade informacional, os professores necessitam sistematizar sua prática pedagógica, utilizando, para tanto, recursos tecnológicos que proporcionem temas contextualizados e acompanhados de sons, imagens e vídeos. Diversificar a linguagem de ensino e tecnológica oportuniza dinamismo, maior interação e compartilhamento de saberes. 0 protagonismo do conhecimento não fica centrado somente no professor, mas surgem sinais de reciprocidade entre professor e alunos que dão significados aos conhecimentos debatidos.

Nesse contexto, insere-se o uso do computador interativo, “[...] ou também o chamado por amarelão; trouxe resultados positivos, pois desperta o interesse dos alunos e possibilita uma maior participação nas aulas" (P1). O computador interativo atrai os alunos por estar associado aos recursos de multimídia, permitindo ampliar as ações do professor e, consequentemente, o universo do aluno.

Além disso, o protagonista ainda acrescenta que recursos desse tipo podem unir pessoas em torno de um tema comum, uma multiplicidade de ideias e trocas de experiências. Esse tipo de atividade promove o envolvimento de todos os alunos. As relações aumentam a partir do uso da LDI, permitindo ao aluno visualizar, questionar, debater e resolver os problemas mentalmente e tocando na tela. Para o professor P2:

É um recurso com um potencial enorme, bem proveitosa, ampliando a possibilidade do aluno aprender não restringindo ao giz, pois o aluno olha pro quadro e não enxerga as figuras de forma adequada, tanto com relação à sua forma como seus elementos permitindo que o aluno aprenda errado.

Ressalta-se que a LDI proporciona um ensino pelo tato, dando a liberdade de o aluno fazer as suas próprias escolhas e mexer nas atividades que despertam curiosidade. Segundo Oliveira (2018, p. 55) "na modalidade tátil, o uso da LDI possibilita o aluno tocar na tela e nela interagir [...]", o que desperta a atenção e o pensar. Entre os professores protagonistas, dois entrevistados mencionaram não ter conhecimento dessa funcionalidade do computador interativo com lousa digital.

O maior impasse foi a ausência da formação continuada para conhecer realmente o verdadeiro potencial desse instrumento tecnológico, em como manuseá-lo. Um desses professores ainda mencionou que: "Somente o bibliotecário participou da formação na Secretaria de Educação, no entanto, nada foi repassado para os professores, estamos aprendendo o básico no dia a dia em sala de aula” (P3).

Diante do diálogo com os protagonistas, foi observado que há uma inserção do computador interativo na sala de aula. Em algumas ocasiões, observou-se nas falas que outros meios tecnológicos colaboraram para os professores aprenderem a manusear e aplicar o referido instrumento em suas aulas. P2 e P3 corroboram isso, expressando o seguinte: "Não participei de formação, mas aprendi a manu- 
sear por curiosidade, assistindo vídeo tutorial no YouTube para conhecer melhor essa tecnologia e de como utilizar nas aulas de Matemática”. No contexto do ensino de Matemática, destacaram-se alguns eixos matemáticos e softwares que foram trabalhados em sala de aula, a exemplo da geometria:

Geometria é o conteúdo, pois permite mostrar os desenhos geométricos, o ponto médio de um segmento de reta, mudar as cores das retas e deixando mais nítido para o aluno, por isso vejo a geometria como o principal conteúdo a ser trabalhado com esse recurso, principalmente utilizando o Geogebra (P3).

Esse professor deixa claro que o computador interativo permite melhor compreensão dos conceitos geométricos, pelo fato de transpor mais visivelmente seus elementos. P3 ainda acrescenta que o quadro-negro não propõe visibilidade por completo de um sólido geométrico. Assim, a tecnologia surgiu para colaborar nesse sentido e em outros aspectos da Matemática. Todavia, percebe-se maior preocupação dos professores no que diz respeito a aprender e assim fazer algo diferente. Eles expressam, em suas falas, a relevância de inserir as tecnologias no ensino de Matemática. Em relação ao computador interativo com lousa digital,

já tem o Geogebra, o plano cartesiano e algumas figuras geométricas, possibilitando ao professor aprendizagem, assim como para os seus alunos. Ao professor pesquisar, dar aula com esse instrumento desenvolve outros saberes, e na sala aprende mais ainda a partir das discussões. De modo geral, a educação não se move sem tecnologia (P3).

Esse protagonista ainda acrescenta que utiliza o pen drive com segurança, em razão do

sistema operacional ser o Linux, evitando a contaminação de vírus e possíveis gastos com manutenção. Enfim, a contribuição maior do laranjão para minha prática pedagógica é o aumento do aprendizado do aluno, pois facilita na ilustração e visualização de elementos que o giz impossibilita. A precisão em um gráfico mostrada nesse instrumento é bem maior, assim como ver as retas paralelas, o perpendicularismo a partir de exemplos ilustrativos e bem ampliados (P3).

Assim sendo, as narrativas dos professores de Matemática e as reflexões desenvolvidas revelam fatos da memória, das experiências e das vivências com o Projetor Prolnfo com o propósito de construir conhecimento matemático de forma dinâmica e atrativa para seus alunos. Para estes, propor diferentes alternativas metodológicas, principalmente aquelas semelhantes ao seu contexto social, permite ações didáticas concretas e relações subjetivas que contribuem para a aprendizagem do aluno e para o crescimento profissional do professor. 


\section{REFLEXÕES FINAIS}

Ao narrar as falas dos protagonistas e correlacioná-las com os autores que embasaram esta investigação referente às tecnologias presentes no ensino de Matemática, no caso da rede municipal de Coruripe, notou-se que há um mundo bidimensional presente nas aulas da disciplina, representado por átomos e bits. Trata-se de uma transição da linguagem verbal e escrita a giz para uma linguagem digital apresentada aos alunos por multimídia - formada por vídeos, imagens, hipertextos, áudios, animações e outras combinações presentes nas diferentes tecnologias digitais.

A comunicação, visualização e o tato são primordiais para o ensino de Matemática. Integrar esses elementos ao processo de aprendizagem do aluno exige do professor conhecer realmente os instrumentos a serem utilizados em suas aulas. Todavia, os impasses existem, um bom exemplo foi e está sendo o processo de inserção e integração do computador interativo no ensino de Matemática na rede municipal pela ausência da formação continuada dos professores, derivando em um conhecimento limitado sobre o computador interativo, relacionando-o somente como um projeto. Todavia, esse instrumento também exerce a função de computador e lousa digital. Além disso, tal situação resulta no seu uso restrito em relação aos programas e softwares para o ensino de Matemática.

Desse modo, vale reiterar a relevância da formação inicial ou continuada com foco nas tecnologias no ensino de Matemática, pois, apesar de os professores estarem conectados com o mundo digital, não possuem os conhecimentos instrumentais e pedagógicos para melhor inserir algumas tecnologias em sala de aula de modo a realmente fazê-las contribuir com a aprendizagem, tendo em vista as constantes inovações tecnológicas na educação. 


\section{REFERÊNCIAS}

ARAÚJO, N. Tecnologia na educação. 2009. Disponível em: http://nadson-tecnologia.blogspot.com. br/2009/. Acesso em: 23 jan. 2018.

AZEVEDO, S. M. O PROINFO em Alagoas. Portal do professor - MEC. 2009. Disponível em: portaldoprofessor.mec.gov.br/storage/materiais/0000015046.pdf. Acesso em: 23 jan. 2018.

BARROS, L. M. R.; BARROS, M. E. B. O problema da análise em pesquisa cartográfica. In: PASSOS, E; KASTRUP, V; SILVA, T. (Org.). Pistas do método da cartografia: a experiência e o plano comum. Porto Alegre: Sulina, 2016. p. 15-41.

BASTOS, M. H. C. Do quadro-negro à lousa digital: a história de um dispositivo escolar. Cadernos de história da educação, Uberlândia, n. 4, p. 133-141, 2005.

BRASIL. Programa Nacional de Informática na Educação - Prolnfo. 2017. Disponível em: http://www. fnde.gov.br/programas/PROINFO/sobre-o-plano-ou-programa/sobre-o-PROINFO. Acesso em: 23 jan. 2018 CASTELLS, M. A sociedade em rede: a era da informação, economia, sociedade e cultura. 6. ed., São Paulo: Paz e Terra, 1999. v. 1.

ESTEVES, R. F.; FISCARELLI, S. H.; SOUZA, C. B. A. Lousa digital interativa como instrumento de melhoria da qualidade da educação: um panorama geral. Rev. on line de Política e Gestão Educacional, Araraquara, v. 1 n. 15 p. 186-197, 2013.

GUATTARI, F. Caosmose: um novo paradigma estético. Trad. Ana Lúcia de Oliveira e Lúcia Cláudia Leão. São Paulo: Ed. 34, 1992.

GUIMARÃES, H. M. Concepções, crenças e conhecimento: afinidades e distinções essenciais. Quadrante: revista de investigação em Educação Matemática, v. 19, n. 2, p. 81-102, 2010.

OLIVEIRA, A. S. S. 0 processo de alfabetização com crianças do ensino fundamental mediado pela lousa digital interativa. 2018. Dissertação (Mestrado) - Programa de Pós-Graduação em Educação, Universidade Federal de Sergipe, São Cristóvão, 2018.

OLIVEIRA, C. A. Práticas de multiletramentos e tecnologias digitais no ensino de matemática. In: Simpósio Internacional de Educação e Comunicação - Simeduc, Aracaju, 2017. Anais..., Aracaju, 2017.

OLIVEIRA, E. V. Pedagogia das tecnologias de informação e comunicação (TIC): outros tempos, outros espaços, outros saberes necessários à prática docente. 2017. Dissertação (Mestrado) - 
Programa de Pós-Graduação em Ensino de Ciências e Matemática, Universidade Federal de Sergipe, São Cristóvão, 2017.

PASSOS, E., BARROS, R. B. A cartografia como método de pesquisa-intervenção. In: PASSOS, E; KASTRUP, V; ESCÓSSIA, L. (Org.). Pistas do método da cartografia: Pesquisa intervenção e produção de subjetividade. Porto Alegre: Sulina, 2015. p. 17-31.

SILVA, J. G. Recursos TIC na educação e formação continuada de professores na contemporaneidade. In: VASCONCELOS, C. A. (Org.). Tecnologias, currículo e diversidades: substratos teóricopráticos da/na educação [recurso eletrônico]. São Cristóvão: Editora UFS, 2016.

VASCONCELOS, C. A. Interfaces interativas na educação a distância: estudo sobre cursos de geografia. Recife: Ed. UFPE, 2017.

VICENTIN, F. R. A lousa digital e a aprendizagem do professor que ensina matemática. 2017. Dissertação (Mestrado em Ensino de Ciências e Educação Matemática) - Universidade Estadual de Londrina, Centro de Ciências Exatas, Londrina, 2017. 
1 Mestre em Ensino de Ciências e Matemática - UFS; Professor efetivo da educação básica do município de Maragogi-AL. E-mail: elyton_batista@hotmail.com

2 Pós-Doutor em Educação Contemporânea - UFPE; Prof. do Depto. de Educação e do Programa de Pós-graduação em Ensino de Ciências e Matemática (PPGECIMA) da Universidade Federal de Sergipe - UFS.

E-mail: geopedagogia@yahoo.com.br

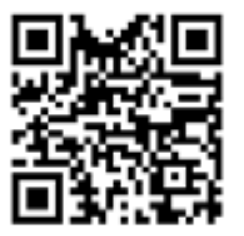

A autenticidade desse artigo pode ser conferida no site https://periodicos. set.edu.br

\section{(2) (1) (2)}

Este artigo é licenciado na modalidade acesso abertosob a Atribuição-Compartilhalgual CC BY-SA

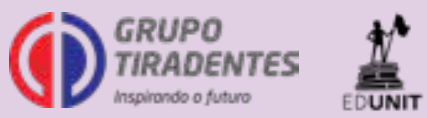

